\title{
Improvements in self-care among patients with diabetes in a remote island in Japan: a pilot study
}

\author{
Ryuichi Ohta ${ }^{1,2}$, and Chikako Mukoyama ${ }^{3}$ \\ ${ }^{1}$ Community Care, Unnan City Hospital, Japan \\ ${ }^{2}$ Minamidaito Clinic, Okinawa Prefectural Nambu Medical Center \& Children's Center, Japan \\ ${ }^{3}$ Minamidaito Village Office, Japan
}

\begin{abstract}
Objective: The traits of the inhabitants of rural areas could affect clinical improvements. In the rural areas of Japan, a feeling of competitiveness often exists between the members of a community; this competitiveness could prompt patients to exert efforts in improving their health. This study aimed to assess the effects of competitiveness on the clinical outcomes of patients with diabetes.

Patients and Methods: Between December 2014 and December 2015, a pilot study was conducted among patients with diabetes to assess the effects of an intervention on improvements in self-care, quality of life (QOL), and hemoglobin A1c (HbAlc) values. The intervention included showing each participant a histogram of the $\mathrm{HbAlc}$ levels of all patients visiting a clinic in the remote island as well as the location of their own HbA1c level on the histogram. Once every 4 months, the patient's HbAlc level was assessed by conducting a blood test, and the self-care agency questionnaire 30 (SCAQ30) was administered by a community health nurse. After 12 months, changes in HbAlc values, SCAQ30 score, and MOS 36-item short-form health survey score were evaluated.

Results: Sixty-four participants (mean age: 63.6 years; male-tofemale ratio: 35:29) were included in the final analysis (follow-up rate: $71.1 \%$ ). In participants with $\mathrm{HbA} 1 \mathrm{c}$ values $\geq 8 \%$ and $<8 \%$ at baseline, the HbA1c value decreased by $1.39(\mathrm{p}<0.001)$ and 0.12 $(\mathrm{p}=0.137)$, respectively, and the mean SCAQ30 score increased by 14.94 and 6.39 points $(p<0.001)$, respectively. Furthermore, in participants with an $\mathrm{HbAlc}$ value $\geq 8 \%$, the mean mental component summary score increased by 5.64 points $(p=0.019)$, and the mean role/social component summary score decreased by 6.04 points $(\mathrm{p}=0.022)$.
\end{abstract}

Received: July 14, 2017

Accepted: June 2, 2018

Correspondence: Ryuichi Ohta, MD, Unnan City Hospital, 96-1 Iida, Daito-cho, Unnan, Shimane 699-1221, Japan

E-mail: ryuichiohta0120@gmail.com

This is an open-access article distributed under the terms of the Creative Commons Attribution Non-Commercial No Derivatives (by-nc-nd) License $<$ http://creativecommons.org/licenses/by-nc-nd/4.0/>.
Conclusion: The continuous stimulation of competitiveness may help improve the health conditions of patients with diabetes. Moreover, collaboration between rural clinics and community health nurses may also be important.

Key words: comparison, diabetes, Japan, rural island, SCAQ30, SF-36

(J Rural Med 2018; 13(2): 134-140)

\section{Introduction}

To better manage the condition of patients with diabetes, a variety of interventions are available. The chronic care model $(\mathrm{CCM})$ is a framework for improving disease interventions. With the use of the CCM, collaboration between communities and medical institutions as well as the total care of patients might lead to improvements in selfmanagement and disease control ${ }^{1}$. Moreover, the CCM may improve clinical indicators, such as glycated hemoglobin (HbA1c), low-density lipoprotein cholesterol, and body mass index $(\mathrm{BMI})^{2},{ }^{23}$. With regard to the implementation of the CCM, measuring the HbAlc level, presenting the results to patients with diabetes on the same day ${ }^{4)}$, and comparing the patients' score with those with normal HbAlc in front of the patients ${ }^{5)}$ may be effective in improving patient outcomes. Such approach may improve the quality of life (QOL) of patients with diabetes from a single health institution, whereas improvements in clinical outcomes, such as HbAlc values, may be further improved by collaborating with other hospitals or clinics ${ }^{6,7)}$. In Minamidaito Island, Japan (Figure 1), rural clinics collaborate with public health nurses. A previous study conducted in a rural island in Japan has shown that the general feeling of competitiveness with other individuals in the rural community was among the traits of the inhabitants ${ }^{8}$. This trait may contribute in improving the self-control skills of patients with diabetes and 


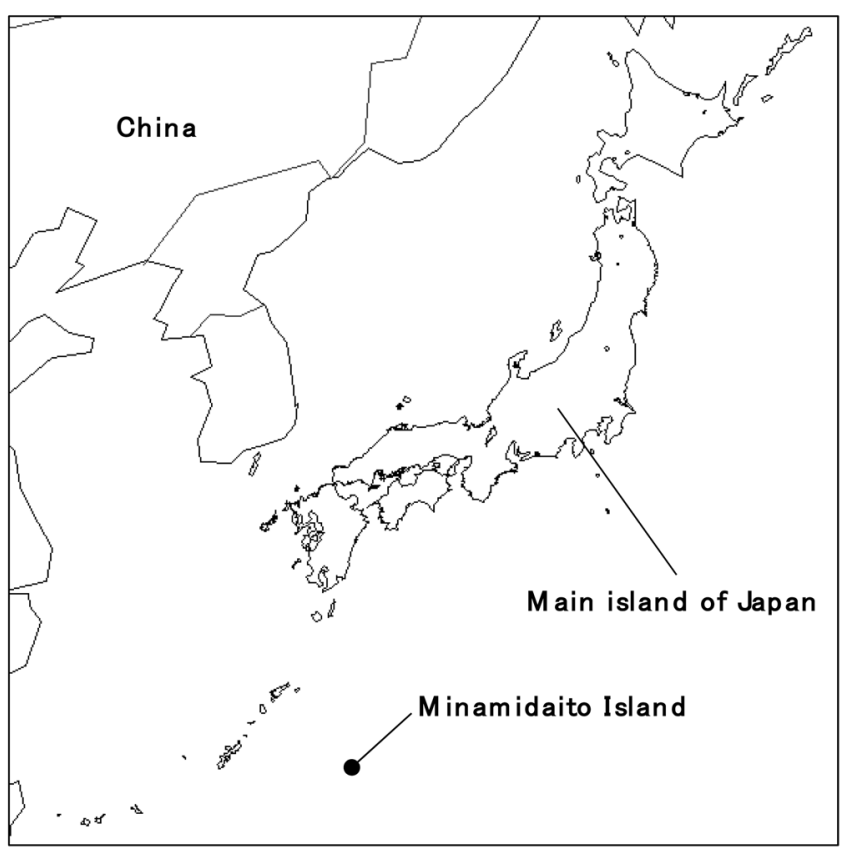

Figure 1 Location of Minamidaito Island.

clinical indicators. However, no previous studies have investigated whether between-patient comparisons of HbAlc values among patients with diabetes in a rural island could affect disease control. In addition, although interventions involving public health nurses in Japan may improve the selfcare and QOL of patients, whether these interventions could improve clinical indicators, such as HbAlc values ${ }^{9}$, is not fully elucidated.

Accordingly, this study on patients with diabetes in a rural island has examined the effectiveness of between-patient comparisons on improvements in self-control abilities, QOL, and HbAlc levels. To assess the effects of betweenpatient comparisons, the HbAlc values of the patients were plotted as a histogram, which helps each patient to compare themselves to other patients. We hypothesized that betweenpatient comparison could stimulate and motivate the patients to control their diseases. The present study aimed to identify whether comparison among rural patients with diabetes and collaboration between a rural clinic and public health nurse could improve the self-control abilities, QOLs, and HbA1c values of patients.

\section{Patients and Methods}

This pilot study investigated the effects of betweenpatient comparison among rural patients with diabetes and collaboration between a rural clinic and public health nurse on improving patient outcomes. The study was performed

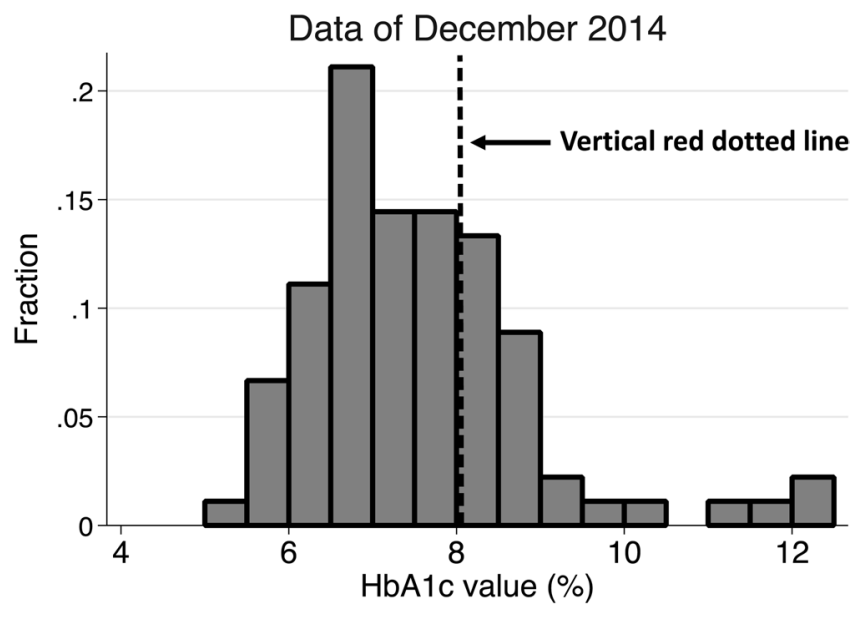

Figure 2 Histogram of the hemoglobin A1c (HbA1c) data.

in a Minamidaito Clinic at Okinawa Nanbu Medical Center/Children's Medical Center, Okinawa, Japan. The center is located approximately $400 \mathrm{~km}$ east of the mainland of Okinawa and is the only medical institution in the island of Minamidaito. As of June 2014, the population of the island was 1315 . The participants were rural patients with diabetes who regularly visited the clinic in November 2014. During every visit, the participants were educated about the importance of balance between food and exercise based on data from the Japanese Diabetes Society. With regard to exercise, the participants were recommended to exercise for 20 minutes more than three times per week. As regards food, the participants were recommended to eat a balanced diet and to reduce carbohydrate intake by avoiding food, such as rice and noodles. Patients who had dementia and difficulty speaking, listening, and/or writing were excluded. To assess the self-care abilities and QOL of the patients, the self-care agency questionnaire 30 (SCAQ30) and MOS 36-item shortform health survey (SF-36; Japanese version) were administered, respectively. The following baseline data were collected from the medical charts of the participants: age, sex, body weight, height, BMI, blood pressure, low-density lipoprotein cholesterol level, HbAlc value, comorbidities (hypertension and hyperlipidemia), complications (neuropathy, retinopathy, and nephropathy), and intake of medications for diabetes.

We created the histogram of HbAlc values using data measured until November 2014. In the histogram, a vertical red dotted line was inserted at an HbAlc value $=8 \%$, which is the maximal proper score for diabetes according to the Japanese Diabetes Society (Figure 2). At each patient visit, the first author showed the histogram to the patient and revealed his or her position on it. In the process, the first 
author further explained whether the patient was "worse" or "better" than other patients with diabetes in the island using the vertical line as a reference. Next, the patients were moved to another room, and the public health nurse educated them about self-care abilities based on the results of the SCAQ30. Blood tests were performed every 4 months. The contents of the histogram were updated monthly based on the new HbAlc data, and the updated histogram was presented to the patients at each follow-up. The public health nurse administered the SCAQ30 questionnaire at baseline and after 4, 8, and 12 months and the SF-36 survey form at baseline and after 12 months.

The SCAQ309) questionnaire was designed to assess the self-care abilities of the patients and to reflect the characteristics of Japanese patients with chronic diseases. It comprises five categories: ability of interest in health, ability of choice, ability of adjustment, ability of continuity, and ability of obtaining support. Higher scores indicate higher self-care abilities. In addition, by referring to the results of the questionnaire, interventions associated with patients' lifestyles can be provided. The Japanese version of the SF-36 survey ${ }^{10)}$ questionnaire was designed to measure health-related QOL with sufficient validity and reliability. It comprises three components: physical component summary (PCS), mental component summary (MCS), and role/social component summary (RCS).

\section{Statistical analysis}

In this research, the primary outcome was the change in HbAlc value from pre-intervention to post-intervention, and the secondary outcomes were the changes in the SCAQ30 and SF-36 scores from pre-intervention to post-intervention. After assessing the normality of the variables using the Kolmogorov-Smirnov test, parametric or nonparametric statistics were used accordingly. These statistics included the paired t-test, Wilcoxon signed-rank test, and binomial test. Repeated measures of variance was used to investigate the differences in the changes between the groups. Differences within and among groups were significant when the significance level was 5\% or lower. Data analysis was carried out using Stata 12 for Mac (StataCorp, College Station, TX, the USA).

\section{Ethics approval}

The research was approved by the clinical ethics committee of Okinawa Nambu Medical Center/Children's Medical Center (approval number: 2014-9). Informed consent was obtained from all participants. Confidentiality of the information and assurance that their health would not be jeopardized were guaranteed to all participants. Furthermore, the patients were informed that their participation was vol- untary and that they could withdraw from the research at any time.

\section{Results}

At baseline, 90 participants were enrolled. The followup duration was 1 year, that is, from December 2014 to December 2015. During the follow-up, 27 participants dropped out owing to moving from the island (eight participants), admission to hospitals in the mainland of Okinawa (five participants), loss of regular follow-up (five participants), desire to withdraw from the research (five participants), and death (four participants). The characteristics of the patients are shown in Table 1. No significant differences were observed in any of the baseline characteristics of the participants (HbA1c values $<8 \%$ and $\geq 8 \%$ ).

\section{Changes in HbAlc values over time}

At 12 months, the mean HbAlc value had decreased by 0.467 percentage points (from $7.40 \%$ before the intervention to 6.93 after the intervention; $95 \%$ confidence interval [CI]: $0.23-0.69, \mathrm{p}<0.001)$. In the participants with an HbAlc value $\geq 8 \%$, the value decreased by 1.39 percentage points (from $8.82 \%$ to $7.42 \%$; 95\% CI: $0.86-1.93$, p $<0.001$ ), whereas it decreased by 0.12 percentage points in the participants with an $\mathrm{HbAlc}$ value $<8 \%$ (from $6.88 \%$ to $6.75 \%$; $95 \% \mathrm{CI}$ : $0.29-0.41, p=0.137$ ) (Table 2). A trend of reducing HbA1c values was observed among the participants with an HbAlc value $\geq 8 \%$ (Figure 3 ).

\section{Changes in the SCAQ30 score}

The mean SCAQ30 score increased by 8.69 points over the 12-month study period (from 114.84 before the intervention to 123.53 after the intervention; 95\% CI: 3.84-13.55, p $<0.001$ ). In the participants with an HbAlc value $\geq 8 \%$, the mean score increased by 14.94 points (from 112.88 to 127.82 ; 95\% CI: $6.00-23.88, \mathrm{p}<0.001)$, whereas in the participants with an $\mathrm{HbAlc}$ value $<8 \%$, it increased by 6.39 points (from 115.56 to 121.96 ; 95\% CI: 0.57-12.22, $\mathrm{p}<0.001$ ) (Table 2). An increasing trend in the SCAQ30 score was observed in both participants with $\mathrm{HbAlc}$ values $\geq 8 \%$ and $<8 \%$ (Figure 4).

\section{Changes in the SF-36 components (PCS, MCS, and RCS)}

The mean PCS score decreased by 2.54 after the intervention (from 42.9 points before the intervention to 40.3 points after the intervention; 95\% CI: $-0.64-5.71, \mathrm{p}=0.115$ ). In the participants with an $\mathrm{HbAlc}$ value $\geq 8 \%$, the mean score decreased by 2.31 points (from 47.36 to 45.05 ; $95 \% \mathrm{CI}$ : $-3.47-8.11, \mathrm{p}=0.409)$. In the participants with an HbA1c value $<8 \%$, the mean score decreased by 3.09 points (from 
Table 1 Baseline comparison of the means of the study variables

\begin{tabular}{lccccc}
\hline \multirow{2}{*}{ Variable } & \multicolumn{2}{c}{ HbA1c $<8 \%(\mathrm{n}=46)$} & \multicolumn{2}{c}{ HbA1c $\geq 8 \%(\mathrm{n}=17)$} & \multirow{2}{*}{ p-value } \\
\cline { 2 - 4 } & Mean & SD & Mean & SD & \\
\hline Demographic & & & & & \\
Age (years) & 64.47 & 1.62 & 59.71 & 1.62 & 0.11 \\
Male sex (\%) & 52.17 & 7.36 & 64.71 & 11.59 & 0.37 \\
Alcohol (\%) & 50 & 7.37 & 52.94 & 12.11 & 0.85 \\
Smoking (\%) & 32.61 & 6.91 & 35.29 & 11.59 & 0.84 \\
Clinical & & & & & \\
BMI & 26.94 & 0.59 & 27.51 & 1.01 & 0.62 \\
HbA1c & 6.87 & 0.09 & 8.9 & 1.09 & $<0.01$ \\
Hypertension (\%) & 76.08 & 6.28 & 88.23 & 7.81 & 0.29 \\
Dyslipidemia (\%) & 65.21 & 7.02 & 76.47 & 10.28 & 0.39 \\
SF-36 & & & & & \\
PCS & 41.23 & 2.12 & 47.36 & 1.91 & 0.12 \\
MCS & 54.54 & 1.51 & 51.79 & 1.25 & 0.33 \\
RCS & 55.35 & 1.55 & 56.64 & 1.41 & 0.64 \\
SCAQ30 & 115.56 & 21.84 & 112.88 & 18.55 & 0.65 \\
Medication (\%) & & & & & \\
SU & 26.00 & 0.62 & 55.56 & 1.21 & 0.02 \\
Alpha-GI & 34.00 & 0.68 & 38.89 & 1.18 & 0.71 \\
Biguanides & 50.00 & 0.71 & 66.67 & 1.14 & 0.23 \\
DPP-4 inhibitors & 18.00 & 0.55 & 22.22 & 1.01 & 0.70 \\
Thiazolidinediones & 0 & 0 & 0.56 & 0.56 & 0.09 \\
Insulin & 10.00 & 0.43 & 27.78 & 1.08 & 0.069 \\
\hline
\end{tabular}

HbA1c: hemoglobin A1c; BMI: body mass index; SF-36: MOS 36-item short-form health survey; PCS: physical component summary; MCS: mental component summary; RCS: role/social component summary; SCAQ30: self-care agency questionnaire 30.

Table 2 One-way analysis of variance (ANOVA) for the four measurements in the two groups

\begin{tabular}{|c|c|c|c|c|c|c|}
\hline & & Baseline & 4 months & 8 months & 12 months & $\mathrm{p}$-value \\
\hline \multicolumn{7}{|l|}{$\mathrm{HbA} 1 \mathrm{c}<8$} \\
\hline HbAlc & & $6.88 \pm 0.63$ & $6.71 \pm 0.75$ & $6.73 \pm 0.69$ & $6.75 \pm 0.75$ & 0.137 \\
\hline SCAQ & & $115.5 \pm 21.8$ & $120.7 \pm 20.1$ & $124 \pm 18.3$ & $121.9 \pm 18.9$ & $<0.01$ \\
\hline \multirow[t]{3}{*}{ SF-36 } & PCS & $41.2 \pm 2.1$ & & & $38.6 \pm 2.1$ & 0.181 \\
\hline & MCS & $54.5 \pm 1.5$ & & & $56 \pm 1.5$ & 0.176 \\
\hline & RCS & $55.4 \pm 1.6$ & & & $54.1 \pm 1.6$ & 0.373 \\
\hline \multicolumn{7}{|l|}{$\mathrm{HbA} 1 \mathrm{c} \geq 8$} \\
\hline $\mathrm{HbAlc}$ & & $8.82 \pm 0.92$ & $7.99 \pm 0.95$ & $7.51 \pm 0.97$ & $7.43 \pm 0.81$ & $<0.01$ \\
\hline SCAQ & & $112.9 \pm 18.5$ & $114.8 \pm 24.2$ & $122.1 \pm 14.2$ & $127.8 \pm 14.4$ & $<0.01$ \\
\hline \multirow[t]{3}{*}{ SF-36 } & PCS & $47.4 \pm 1.9$ & & & $45.4 \pm 1.9$ & 0.413 \\
\hline & MCS & $51.8 \pm 1.6$ & & & $57.4 \pm 3.3$ & 0.019 \\
\hline & $\mathrm{RCS}$ & $56.6 \pm 1.4$ & & & $50.6 \pm 2.7$ & 0.022 \\
\hline
\end{tabular}

HbA1c: hemoglobin A1c; BMI: body mass index; SF-36: MOS 36-item short-form health survey; PCS: physical component summary; MCS: mental component summary; RCS: role/social component summary; SCAQ30: self-care agency questionnaire 30.

41.23 to 38.61 ; $95 \% \mathrm{CI}:-1.29-6.54, \mathrm{p}=0.184)$. Overall, the mean MCS score increased by 2.54 points (from 53.79 before the intervention to 56.88 after the intervention; $95 \%$ CI: $0.51-5.68, \mathrm{p}=0.019)$. In the participants with HbAlc values $\geq 8 \%$ and $<8 \%$, the mean score increased by 5.64 (from 51.76 to $57.39 ; 95 \% \mathrm{CI}:-1.04-10.22, \mathrm{p}=0.019$ ) and 2.15 (from 54.54 to $56.69 ; 95 \%$ CI: $-1.01--5.32, \mathrm{p}=0.178$ ), respectively. Finally, the mean RCS score decreased by 2.6 


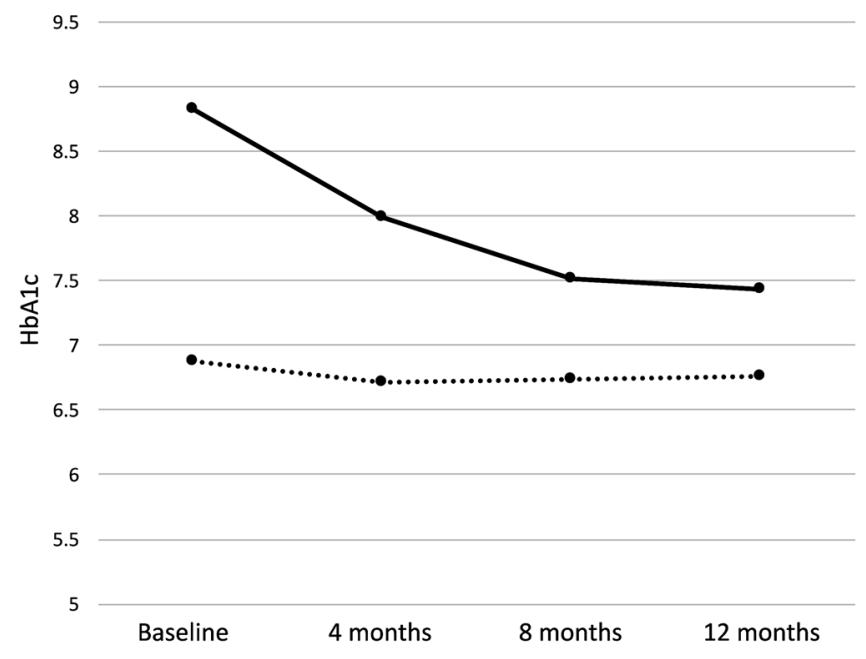

Figure 3 Means of the hemoglobin A1c (HbA1c) values according to the group and time of measurement. Dotted line: $\mathrm{HbAlc}<8$, Solid line: $\mathrm{HbAlc} \geq 8$.

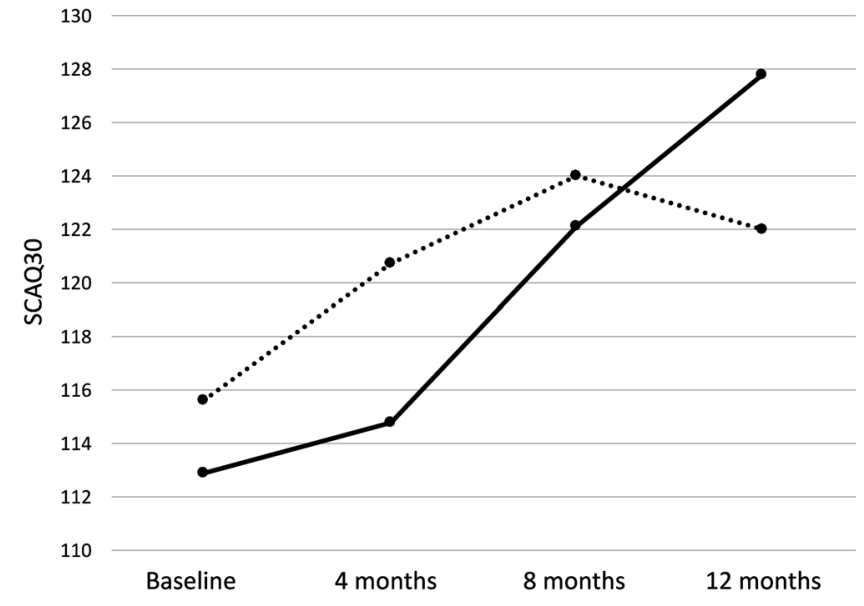

Figure 4 Means of the self-care agency questionnaire 30 (SCAQ30) score according to the hemoglobin $\mathrm{A} 1 \mathrm{c}(\mathrm{HbAlc})$ group and time of measurement. Dotted line: HbAlc $<8$, Solid line: HbAlc $\geq 8$.

points (from 55.69 before the intervention to 53.09 after the intervention; $95 \% \mathrm{CI}:-0.05--5.15, \mathrm{p}=0.045$ ). In the participants with $\mathrm{HbAlc}$ values $\geq 8 \%$ and $<8 \%$, the mean score decreased by 6.04 (from 56.63 to 50.6 ; $95 \%$ CI: $-0.99-11.08$, p $=0.022$ ) and 1.33 (from 41.23 to $54.02 ; 95 \%$ CI: $-4.31-1.65$, $\mathrm{p}=0.37$ ), respectively (Table 2 ).

\section{Discussion}

This pilot study showed that between-patient comparison among rural patients with diabetes and collaboration between a rural clinic and public health nurse may improve both the self-control skills and HbAlc levels of the patients. The "social comparison activity"11) approach was used in the present study, and it improved the motivation for controlling diseases among patients with various chronic conditions ${ }^{12}$. Moreover, there are two kinds of social comparison activities, namely, upward and downward comparisons ${ }^{13}$. Upward comparison refers to comparing oneself with others who are doing better, whereas downward comparison refers to comparing oneself with others who are doing worse. The method of comparison that is better for each individual patient may depend on the patient's need for advice. There are two kinds of advice: self-promotion and self-regulation. Focusing on self-promotion refers to providing advice associated with obtaining positive outcomes, whereas focusing on self-regulation refers to providing advice associated with avoiding negative outcomes ${ }^{13)}$. Well-controlled patients who are more likely to focus on positive outcomes should be approached using the upward comparison, whereas poorly controlled patients who are more likely to focus on avoiding negative outcomes should be approached using the downward comparison ${ }^{13}$. Furthermore, behavioral programs may be beneficial for individuals with suboptimal or poor glycemic control more than those with good control ${ }^{14)}$. In this study, the downward comparison was used in participants with an $\mathrm{HbAlc}$ value $<8 \%$, and the upward comparison was utilized in participants with an HbAlc value $>8 \%$. The selfcontrol abilities of both groups improved, which indicates that an HbAlc cutoff value of 8 is an appropriate basis for determining the types of intervention.

The strong connections among rural inhabitants might help enhance changes in self-control abilities and some aspects of QOL. In particular, in Japanese rural communities, strong human connections exist, and the inhabitants are extremely anxious and concerned about each other ${ }^{8}$. This sense of consciousness among the inhabitants might cause increased competition when they are shown competitive data. This leads to improvements in HbAlc values and SCAQ30 scores, as shown in the present study. Furthermore, the MCS score increased and the RCS score decreased significantly only in participants with an HbAlc value $\geq 8 \%$. The patients' understanding and awareness of their diseases may be one of the factors that affect MCS and RCS scores ${ }^{15)}$. If patients do not understand their diseases, their lack of awareness may have negative effects on their QOL. The intervention used in the present study might stimulate and motivate patients to control their diseases, which could improve MCS scores. By contrast, the between-patient comparison used in this study might provide opportunities for participants to identify the severity of their diseases and to think about themselves more objectively, which in turn 
could make them feel embarrassed about their conditions because of a poor understanding of their diseases. In this study, the participants with an HbAlc value $\geq 8 \%$ were informed about both their diseases and interventions, thereby stimulating and motivating them through shared knowledge of unfavorable information. This intervention may not improve the patients' understanding of their diseases and may instead increase their disease-associated embarrassment because they might negatively perceive the information that was provided.

In addition to the comparative nature of the intervention, the continuous intervention of the same public health nurse may have helped in improving the self-care abilities of the patients with diabetes in the rural island in the present study. The same public health nurse discussed the positive and negative points with the patients using the SCAQ30. This process might result in a good nurse-patient relationships, which is essential not only in the treatment of patients but also in their behavioral modification. Better relationships are associated with better results ${ }^{16}$. The nurse in the present study lived on the same island as the patients, which meant that she understood the patients and the perspective of the island's inhabitants. For example, various cultures exist in the rural islands of Japan, and respect and empathy for the inhabitants' culture may enable medical staff to organize appropriate interventions ${ }^{17}{ }^{18}$. When using the SCAQ30, the medical staff can adjust the intervention to the patients' satisfaction"). In this study, the public health nurse discussed the patients' health and diseases by considering their social and cultural background and advised them by considering the stance of the citizens, which might improve the use of the SCAQ30 and lead to better outcomes. However, this intervention can impose a substantial burden on the public health nurse. In practice, public health nurses do not generally work for prolonged periods in the same rural island in Japan possibly because of excessive work ${ }^{19}$. To continue improving the self-care abilities of the citizens, a health care system for the whole island that is not dependent on a singlemember medical staff must be established.

The present study has some limitations. First, the use of the SCAQ30 might depend on the ability and experience of the public health nurse. Experienced public health nurses might be able to communicate with the patients more effectively ${ }^{20,21)}$. However, in this study, the public health nurse only had a 3-year experience in the island. Second, 26 participants dropped-out during the follow-up period. This might decrease the internal validity of the study. However, the reasons for dropping-out include death and moving away from the island, which could not be avoided. Finally, this study was a pre-post study, and we did not include a nonintervention group. Therefore, the study results may not solely reflect the effects of the intervention on improvements in self-care among patients with diabetes in a remote island in Japan. However, since this study was performed in a rural island, the use of the between-group (intervention vs. nonintervention) comparison design would have been extremely challenging because of the frequent interactions among rural citizens. Further studies should be performed in multiple rural islands in Japan, and a clustered randomized trial or a similar study design should be used to validate our findings.

\section{Conclusion}

Comparison among rural patients with diabetes and collaboration between rural clinics and public health nurses can be effective techniques for improving the clinical outcomes of patients with diabetes. If these techniques can be applied continuously and in collaboration with other health institutions, then the intervention that was first implemented in the present study could be even more effective and sustainable.

\section{Acknowledgements}

We would like to thank all the patients and medical staff in the Minamidaito Island, Okinawa, Japan, for participating in the research, supporting our work, and helping in obtaining high-quality results.

\section{References}

1. Piatt GA, Orchard TJ, Emerson S, et al. Translating the chronic care model into the community: results from a randomized controlled trial of a multifaceted diabetes care intervention. Diabetes Care 2006; 29: 811-817. [Medline] [CrossRef]

2. Philis-Tsimikas A, Walker C, Rivard L, et al. Project Dulce. Improvement in diabetes care of underinsured patients enrolled in project dulce: a community-based, culturally appropriate, nurse case management and peer education diabetes care model. Diabetes Care 2004; 27: 110-115. [Medline] [CrossRef]

3. Sunaert P, Bastiaens H, Nobels F, et al. Effectiveness of the introduction of a Chronic Care Model-based program for type 2 diabetes in Belgium. BMC Health Serv Res 2010; 10: 207. [Medline] [CrossRef]

4. Cagliero E, Levina EV, Nathan DM. Immediate feedback of HbA1c levels improves glycemic control in type 1 and insulin-treated type 2 diabetic patients. Diabetes Care 1999; 22: 1785-1789. [Medline] [CrossRef]

5. Heisler M, Piette JD, Spencer M, et al. The relationship between knowledge of recent $\mathrm{HbA1c}$ values and diabetes care understanding and self-management. Diabetes Care 2005; 28: 816-822. [Medline] [CrossRef]

6. Norris SL, Chowdhury FM, Van Le K, et al. Effectiveness of community health workers in the care of persons with diabe- 
tes. Diabet Med 2006; 23: 544-556. [Medline] [CrossRef]

7. Gallegos EC, Ovalle-Berúmen F, Gomez-Meza MV. Metabolic control of adults with type 2 diabetes mellitus through education and counseling. J Nurs Scholarsh 2006; 38: 344-351. [Medline] [CrossRef]

8. Ogawa T, Saito S. A review of studies on "Health" of the elderly living in islands. Bulletin of The University of Shimane Izumo Campus 2015; 10: 17-24 (in Japanese).

9. Honjo J. Revision of the Self-Care Agency Questionnaire for patients with chronic illness. J Jpn Acad Nurs Sci 2001; 21 : 29-39 (in Japanese). [CrossRef]

10. Fukuhara S, Bito S, Green J, et al. Translation, adaptation, and validation of the SF-36 Health Survey for use in Japan. J Clin Epidemiol 1998; 51: 1037-1044. [Medline] [CrossRef]

11. Blanton H, Buunk BP, Gibbons FX, et al. When better-thanothers compare upward: Choice of comparison and comparative evaluation as independent predictors of academic performance. J Pers Soc Psychol 1999; 76: 420-430. [CrossRef]

12. Schokker MC, Keers JC, Bouma J, et al. The impact of social comparison information on motivation in patients with diabetes as a function of regulatory focus and self-efficacy. Health Psychol 2010; 29: 438-445. [Medline] [CrossRef]

13. Taylor SE, Lobel M. Social comparison activity under threat: downward evaluation and upward contacts. Psychol Rev 1989; 96: 569-575. [Medline] [CrossRef]

14. Pillay J, Armstrong MJ, Butalia S, et al. Behavioral programs for type 2 diabetes mellitus: a systematic review and network meta-analysis. Ann Intern Med 2015; 163: 848-860. [Medline] [CrossRef]

15. Kalda R, Rätsep A, Lember M. Predictors of quality of life of patients with type 2 diabetes. Patient Prefer Adherence 2008; 2: 21-26. [Medline]

16. Kourkouta L, Papathanasiou IV. Communication in nursing practice. Mater Sociomed 2014; 26: 65-67. [Medline] [CrossRef]

17. Anton CE, Lawrence C. Home is where the heart is: The effect of place of residence on place attachment and community participation. J Environ Psychol 2014; 40: 451-461. [CrossRef]

18. Baldwin C, Smith T, Jacobson C. Love of the land: Socialecological connectivity of rural landholders. J Rural Stud 2017; 51: 37-52. [CrossRef]

19. Kawasaki M, Nagayoshi R, Makiuchi S, et al. Advantages and disadvantages of the public health nurse system in Okinawa as well as abilities of public health nurses to be taken over. Journal of Okinawa Prefectural College of Nursing 2012; 13: 39-48 (in Japanese).

20. Sherko E, Sotiri E, Lika E. Therapeutic communication. JAHR 2013; 4: 457-466.

21. Wagner EH. The role of patient care teams in chronic disease management. BMJ 2000; 320: 569-572. [Medline] [CrossRef] 